\title{
REPRESENTAÇÕES DE HOMEM E NATUREZA EM FILMES DE ANIMAÇÃO: PROBLEMATIZAÇÕES DE UMA PEDAGOGIA CULTURAL
}

\author{
Gisele Ruiz Silva ${ }^{1}$ \\ Camila Magalhães ${ }^{2}$ \\ Virgínia Tavares Vieira ${ }^{3}$
}

\begin{abstract}
Resumo: $\mathrm{O}$ artigo analisa as representações de homem e de natureza que circulam nos filmes de animação da série Madagascar produzidos nos anos de 2005, 2008 e 2012. Tem como objetivo discutir o modo como são produzidas certas verdades a respeito da relação entre homem e natureza e a forma como estas instituem determinados modos de ser sujeito na contemporaneidade. Assumimos como referencial teórico o campo dos Estudos Culturais na vertente pós-estruturalista, operando modestamente com o conceito de problematização desenvolvido pelo filósofo Michel Foucault, traçando uma interlocução com autores do campo da Educação Ambiental. As análises do corpus empírico indicam a mídia cinematográfica como produtivo artefato da cultura que, numa sociedade atravessada por certa vontade de pedagogia, reforça o papel central ocupado pelo homem na relação que estabelece com a natureza, reatualizando o ideal moderno antropocêntrico.
\end{abstract}

Palavras-Chave: Homem-Natureza. Representação. Pedagogia Cultural.

\section{REPRESENTATIONS OF MAN AND NATURE IN ANIMATION FILMS: PROBLEMATIZATIONS OF A CULTURAL PEDAGOGY}

\begin{abstract}
This paper analyses the varied representation of man and nature that is presented in animation movies of Madagascar series, made in 2005, 2008, and 2012. It has as objective the discussion of the way that some truths are produced when it comes to the relation between man and nature and how they institute determined manners of being a subject in contemporaneity. We assumed as theoretical reference the area of Cultural Studies in the line of post-structuralism, working modestly with the concept of problematizations developed by the philosopher Michel Foucault, drawing an interlocution with authors of Environmental Education area. The analysis of the empirical corpus indicates the cinematographic media as a productive artefact of culture that, in a society crossed by certain desire for pedagogy, reinforces the central function occupied by men in their relation established with nature, updating again the anthropocentric modern ideal.
\end{abstract}

Keywords: Man-Nature. Representation. Cultural Pedagogy.

\footnotetext{
${ }^{1}$ Pedagoga. Mestre e Doutoranda em Educação em Ciências pela Universidade Federal do Rio Grande - FURG. Bolsista CAPES. E-mail: gisaruizsilva@gmail.com

2 Pedagoga. Mestre em Educação Ambiental pela Universidade Federal do Rio Grande - FURG. E-mail: camilapedag@gmail.com

${ }^{3}$ Graduada em Música. Mestre e Doutora em Educação Ambiental pela Universidade Federal do Rio Grande FURG. E-mail: vi violao@yahoo.com.br
}

Momento: diálogos em educação, E-ISSN 2316-3100, v. 26, n. 1, p. 59-73, jan./jun. 2017 


\section{INTRODUÇÃO}

Discussões sobre educação ambiental, natureza e meio ambiente vêm tomando corpo nas últimas décadas. A crise ambiental que se instala no planeta é forte motivadora de intensas pesquisas no campo científico assim como tema frequente em outras instâncias sociais. Interpeladas por tais discussões, traçamos como objetivo de pesquisa discutir as representações de homem e de natureza produzida pela mídia cinematográfica da última década.

Nesta tarefa assumimos como referencial teórico o campo dos Estudos Culturais na vertente pós-estruturalista. Como suporte teórico-metodológico, nos valemos, ainda que modestamente, do conceito de problematização como uma potente ferramenta analítica desenvolvida pelo filósofo francês Michel Foucault. Segundo ele, problematizar consiste no exercício filosófico, em um "trabalho do pensamento" (2010, p. 233). Trata-se não de representar um dado objeto preexistente, nem de criar um objeto inexistente através do discurso.

A problematização, no sentido foucaultiano

é o conjunto das práticas discursivas e não discursivas, que faz alguma coisa entrar no jogo do verdadeiro e do falso e o constitui como objeto para o pensamento (seja sob a forma da reflexão moral, do conhecimento científico, da análise política, etc.) (FOUCAULT, 2010, p. 242).

Assim, na análise empreendida aqui, interessou-nos dar visibilidade às representações de homem e de natureza uma vez que estas, de alguma forma, passam a corroborar determinadas verdades que interpelam os sujeitos na contemporaneidade.

O corpus analítico aqui investigado compreende alguns excertos extraídos dos filmes de animação gráfica Madagascar (2005), Madagascar 2: A Grande Escapada (2008) e Madagascar 3: Os Procurados (2012). Trata-se da história de um grupo de animais que escapam do Zoológico no Central Park (EUA) e, mesmo sem desejarem, acabam na África primeiro filme. Na sequência - segundo e terceiro filmes - tentam retornar ao zoológico, mas, finalmente ao conseguirem chegar em Nova Iorque, descobrem que não desejam mais ali viver.

Na sequência deste artigo, apresentamos como os Estudos Culturas tomam as mídias enquanto artefatos que produzem modos de vida numa sociedade marcada por uma vontade de pedagogia, destacando que tais mídias, em especial os filmes de animação analisados, consistem em propagadoras de significado daquilo que perpassa nossa vida cotidiana. As 
análises, apresentadas a seguir, apontam as relações de forças presentes nas falas das personagens no que se refere às representações de homem e natureza, comumente naturalizadas em nossos discursos.

\section{A MÍDIA CINEMATOGRÁFICA COMO PEDAGOGIA CULTURAL}

Para a perspectiva dos Estudos Culturais, a produção cinematográfica - assim como os jornais, revistas, propagandas de tevê, internet, entre outros - é um artefato cultural. Segundo Silva (1999), ao apresentarem suas mensagens, tais artefatos articulam informação e entretenimento e, nesse processo, nos ensinam modos de ser e de viver no mundo, produzindo verdades, identidades e subjetividades.

Os artefatos culturais atuam como instrumentos que nos ensinam modos de vida. Pensar por esta perspectiva, nos permite assumir que a pedagogia, como estratégia de ensino, não se restringe ao espaço escolar, ou seja, não é apenas no interior das instituições escolares que os discursos escolarizantes atuam e produzem seus efeitos. Segundo Noguera-Ramírez (2009), os anos que findam o século XX marcam um deslocamento de uma sociedade de ensino para uma sociedade de aprendizagem. Em sua tese intitulada Do governamento pedagógico: da sociedade de ensino para a sociedade de aprendizagem, o autor discute a reestruturação social no ocidente no que tange à arte pedagógica. A sociedade moderna é caracterizada por uma profunda marca educativa. Estruturado numa lógica essencialmente iluminista, o conhecimento era algo amplo e generalizado, ou seja, bastava que os sujeitos possuíssem um conhecimento amplo e geral das coisas, era possível se falar sobre várias coisas.

Após a queda do muro de Berlin, em 1989, emerge uma sociedade pós-capitalista. As formas de relação com a produção se deslocam do produto enquanto matéria - o capital, a terra, o trabalho - para uma preocupação muito específica com o conhecimento. A sociedade do final do século XX tem seu foco centrado no conhecimento especializado, a sociedade efetiva-se como uma cidade educativa ou sociedade de aprendizagem. Esse tipo de sociedade implica um espaço público onde diversas aprendizagens acontecem. São "cenários considerados organizações de aprendizagem que levam a constituir verdadeiras cidades de aprendizagem, caracterizadas porque seus componentes (tanto indivíduos quanto organizações) aprendem a aprender” (NOGUERA-RAMÍREZ, 2009, p. 16). 
Essa mudança, no entanto, não aconteceu de uma hora para outra. Houve uma série de deslocamentos que, segundo esse autor, marcam três momentos na história da educação no Ocidente: $1^{\circ}$ ) entre os séculos XVII e XVIII vigorava uma sociedade de ensino centrado na razão de Estado e na constituição de uma forma de ser sujeito. A Didática era o principal campo do saber pedagógico, debruçada a produzir o homem dócil; $2^{\circ}$ ) no final do século XVIII o conceito de educação era voltado para a lógica do Estado Educador, em que a educação era função estatal, centrada especialmente no espaço da escola pública que se expandiu nas distintas camadas sociais. Nesse contexto, as tradições pedagógicas modernas se constituíram, a Teoria do Currículo e a Pedagogia são exemplos de campos do saber que marcam essa época; e $3^{\circ}$ ) no final do século XIX, a educação sai da responsabilidade única do Estado e passa a ser uma das atribuições da sociedade, a ênfase é na atividade do sujeito que não só aprende, mas que aprende a aprender. Cada sujeito se torna um eterno aprendiz responsável por si - essa é a lógica da sociedade da aprendizagem. Aqui a Psicopedagogia ganha o centro da ação com seu conceito de adaptação, experiência ou resolução de problemas.

Assim, de obrigatoriedade imposta pelo Estado, a educação passa a ser uma demanda da população, uma necessidade, um direito, uma exigência. A educação passa a ser uma responsabilidade pessoal e individual. Na sociedade da aprendizagem a estratégia de educação se pauta do convencimento pela verdade, por aquilo que é dito como verdadeiro e não mais pela força. Para cada discurso de verdade há uma pedagogia, para cada pedagogia há uma vontade de governar, de gerir uma determinada forma de ser humano. O aparente distanciamento do Estado da condução da vida das pessoas é, no entanto, uma estratégia de racionalização dos gastos, uma questão de ordem econômica. Ao mesmo tempo em que o Estado se exime da obrigatoriedade com a educação, ele desenvolve estratégias de gerenciamento da população que, por diversos vieses, educam os sujeitos cotidianamente.

Esse cenário indica a constituição de novas práticas culturais, que se tornam elementos fundamentais para o campo dos Estudos Culturais. Com a emergência desse campo de estudos, e de suas articulações com a Educação, houve a possibilidade de se pensar a pedagogia atrelada à cultura, ou seja, aquilo que se ensina e a forma como se ensina está diretamente ligada à cultura. É no interior da cultura que são constituídos e operacionalizados os saberes de um determinado momento histórico. Além disso, a compreensão de que o lugar Momento: diálogos em educação, E-ISSN 2316-3100, v. 26, n. 1, p. 59-73, jan./jun. 2017 
de ensino e aprendizagem é restrito à escola cai por terra, "os modos como as relações de ensino e aprendizagem estão presentes e marcam múltiplas dimensões da vida" (ANDRADE, COSTA, 2015, p. 49), intensificam-se.

A perspectiva dos Estudos Culturais é um campo bastante heterogêneo que possui diferentes influências epistemológicas e políticas. No entanto, como afirma Veiga-Neto (2004, p. 40), “ao salientar o papel do poder - ou talvez se poderia até dizer: ao colocar o poder no centro das significações e identidades culturais - esse campo abre uma frente para que se possa construir uma ponte com o pensamento de Foucault”. É, então, por este viés, dos Estudos Culturais numa perspectiva foucaultiana, que nos movimentaremos na análise do material empírico que escolhemos para este trabalho.

Como anunciamos no início deste artigo, nosso objetivo é analisar as enunciações presente nos filmes de animação Madagascar colocando em evidência as representações de homem e natureza nele presentes, problematizando-as. É preciso, antes, situar a relevância de tomarmos tal elemento como objeto de análise. Trata-se de um artefato cultural, ou seja, de um objeto produzido no interior de uma determinada cultura que é sustentado e dá sustentação aos discursos que veiculam e formam uma sociedade. Diversos são os artefatos culturais que circulam entre nós e que nos ensinam formas de ser e estar neste mundo: jornais, telenovelas, blogs, revistas, filmes, histórias em quadrinhos, cinema, entre outros. O pesquisador Leandro Belinaso Guimarães destaca a relevância desses artefatos na nossa vida cotidiana:

\begin{abstract}
Somente compartilhando os significados que circulam pelas sociedades, seja através das relações de amizade e vizinhança que estabelecemos, dos programas a que assistimos na televisão, dos cursos que fazemos, das revistas e livros que lemos, das notícias que escutamos no rádio, seja através dessas variadas relações que constituímos cotidianamente é que vamos aprendendo a tomar algumas decisões, a ver e a ler de determinada forma as coisas do mundo e a estabelecer relações com os outros e com a natureza. $(2008$, p. 87$)$
\end{abstract}

Tais artefatos carregam consigo uma vontade de pedagogia. Este é um conceito cunhado por Viviane Camozzato e Marisa Costa numa tentativa de abarcar a lógica governamental de nosso tempo. Segundo as autoras, a vontade de pedagogia implica um desejo "de conduzir os indivíduos, engrenando-os numa lógica em que através de cálculos e estatísticas eles são tomados sujeitos de uma determinada configuração" (2015, p. 36). A pedagogia corresponde a um conjunto de saberes e práticas postas em funcionamento para produzir determinadas formas de ser sujeito. Nesse sentido, essa vontade de pedagogia vai 
estar presente nos diferentes artefatos culturais, atuando como uma estratégia educadora dos sujeitos para além dos muros escolares numa sociedade de aprendizagem.

É importante destacar que a vontade de pedagogia está imersa nas relações de poder e de saber que se estabelecem na sociedade, não é imune a elas, muito pelo contrário. Há marcadamente disputas de poder, jogos de tensão, diferentes interesses competindo entre si para dar uma ou outra direção para os indivíduos. Nos filmes analisados tal disputa fica evidente. As cenas e diálogos se dividem em prós e contras a respeito da vida na grande cidade, seja por uma forma de vida aprendida pelas personagens, seja por um instinto natural destes, despertado ao entrarem em contato com a vida selvagem. Nesse contexto, no entanto, o que nos interessa não é nos posicionarmos contra ou a favor do destino das personagens. $\mathrm{O}$ que nos mobiliza é dar visibilidade a essas disputas, é fazer ver as relações de poder-saber que ali se estabelecem e nos conduzem cotidianamente.

Esse posicionamento teórico pressupõe o entendimento de que a cultura está imbricada na produção de diversos significados compartilhados por grupos sociais. Implica admitir ainda que "a representação participa da constituição das coisas, não sendo vista como um mero reflexo dos eventos que se processam no mundo" (WORTMANN, 2001, p.156).

Desta forma, nesse texto, tratamos a mídia como uma grande propagadora de significados, fabricando modos de vida e constituindo sentidos que nos atravessam e participam no processo de produção cultural. Encontramos nos filmes de cinema estratégias de fazer com que quem os assiste, sinta-se identificado com os personagens, com o enredo, com as imagens, com as falas. Essa identificação permite que passemos a nos utilizar daquilo que consumimos, influenciando na produção de conceitos na vida cotidiana de cada um. De acordo com Wortmann:

[...] é em função disso, que ganha importância discutir como meios de expressão/produção cultural, tais como a televisão, o cinema e a literatura (um tipo de produção que de certa forma nos poderia conectar a outros tipos de sociedade) valem-se dos muitos e diferenciados discursos que circulam em tais sociedades, instituindo múltiplas representações que passam a marcar os sujeitos e as suas visões de mundo (2004, p. 152).

Buscamos, assim, analisar o cinema como parte de uma rede de artefatos que trazem consigo muitas representações sobre assuntos que permeiam a vida cotidiana dos espectadores ensinando-nos lições para além dos muros da educação escolarizada, podendo, por tal razão, ser considerado uma pedagogia cultural. 


\section{EXERCÍCIO DE ANÁLISE: FERRAMENTAS TEÓRICO-METODOLÓGICAS EM AÇÃO}

Neste trabalho dedicamo-nos a analisar as representações de homem e de natureza presentes na sequência cinematográfica Madagascar. Na esteira dos Estudos Culturais, entende-se por representação uma prática pela qual os significados são produzidos e circulam no interior de uma dada cultura. Ao mesmo tempo em que dizemos as coisas, que as representamos, estamos constituindo sentido e significado a elas de acordo com os códigos que nos ligam pela cultura que partilhamos. Assim, ao problematizar as representações de homem e de natureza nos filmes analisados, não nos furtamos de produzir significados a essas construções.

Seguindo os ensinamentos de Michel Foucault (2010), o que nos interessa aqui é evidenciar os excertos que narram sobre homem e natureza, mantendo as análises no nível do dito, ou seja, não há a intensão de buscar sentidos ocultos nas narrativas, o que nos importa é o que de fato foi falado, narrado e/ou aquilo que, embora não verbalizado, é dito por meio de imagens, neste caso, por meio das cenas em que as tramas se desenvolvem. A esse respeito, Foucault destaca que ainda que os discursos sejam feitos de signos, eles não os utilizam apenas para designar coisas. Eles, os discursos, fazem mais que isso. “[...] É esse mais que os torna irredutíveis à língua e ao ato da fala. É esse 'mais' que é preciso fazer aparecer e que é preciso descrever" (2010, p. 55) [grifo do autor].

Examinando o material empírico, notamos que nos três filmes fica evidente a naturalização da vida contemporânea no meio urbano. Inicialmente, em Madagascar - filme que origina a série -, os personagens aparecem completamente acostumados com as tecnologias e satisfeitos com a rotina da cidade. A natureza é representada nas primeiras cenas do filme como um lugar marcado por características negativas, como a falta de higiene e a ausência de alimentos - onde o alimento é, exclusivamente, comida industrializada. Mas diante de uma representação tão negativa da natureza, somos surpreendidos com o seguinte diálogo entre os personagens:

Zebra Marty: - O que vocês estão fazendo?

Pinguins: - Cavando até a Antártida. Já viu algum pinguim correndo solto em Nova Iorque? É claro que não. Isso não é natural. Nosso lugar não é aqui. Isso é uma conspiração totalmente pancada. Nós estamos indo pro espaço aberto da Antártida, pra natureza. Isso é que é vida! 
Zebra Marty: - Pra natureza? Será que dá pra ir lá? Parece o máximo! ${ }^{4}$ (MADAGASCAR, 2005).

$\mathrm{Na}$ sequência, enquanto os amigos comemoram o $10^{\circ}$ aniversário da zebra Marty, vemos a hipopótamo Glória e o leão Alex o questionarem quanto ao pedido que fez ao soprar as velas do bolo:

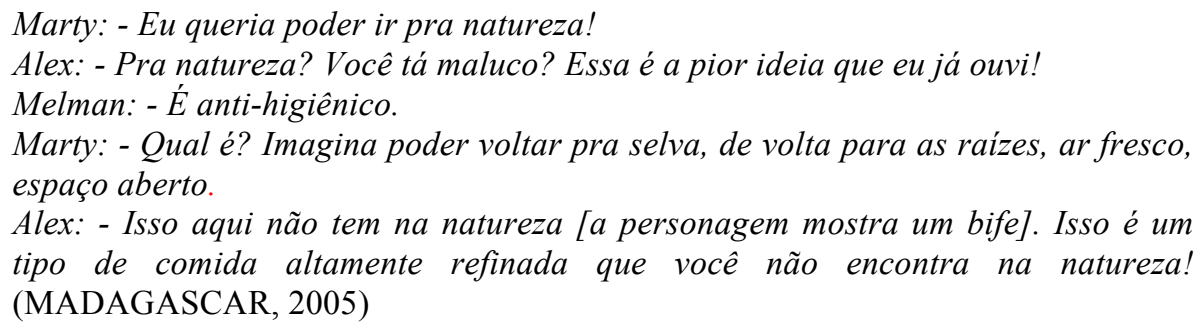

Esse diálogo é marcado pelas expressões das personagens, cujos olhos arregalados demonstram seu com o desejo do amigo Marty. Adaptados ao meio urbano, eles parecem não entender as razões que o levaram desejar voltar à natureza. No entanto, apesar de não estarem de acordo com a ideia de Marty, os animais acabam se envolvendo em uma aventura que os leva acidentalmente para a ilha de Madagascar.

Em outro excerto temos o reforço dessa representação: o homem não é bem-vindo na natureza, pois tem contribuindo para sua transformação, até mesmo sua destruição. Isso fica evidente quando, após chegarem à ilha, os animais do zoológico perguntam aos habitantes do lugar se lá existem homens, na expectativa de que assim pudessem ser ajudados. O que é se de esperar, afinal, quando os animais ainda viviam no zoológico, o que se via eram homens lhes alimentando, cuidando da saúde, os aplaudindo durante as visitas. Em seguida à tal pergunta, as lêmures nativas da ilha de Madagascar apontam para um esqueleto pendurado em uma árvore. Nessa sequência de cenas, seguem as seguintes falas:

\section{Leão Alex: - Vocês não têm uns vivos? [referindo-se aos homens]}

Lêmure: - Não, só mortos. Também, se tivesse muito homem vivo por aqui esse lugar não iria se chamar natureza, não é não? (MADAGASCAR, 2005).

O diálogo entre estes personagens evidencia a coexistência de duas representações diferentes, e aparentemente antagônicas, a respeito da presença do homem: para o leão e seus companheiros (já aculturados) seria uma possibilidade de resolver seus problemas; para a lêmure habitante da ilha (ainda não aculturada), uma ameaça. Diferente do entendimento de natureza que os animais do zoológico possuem, a lêmure entende e vê a natureza ou o espaço natural, como algo intocado pela presença humana, que nessa configuração não é vista como

\footnotetext{
${ }^{4}$ Optamos por destacar os excertos analisados em itálico, a fim de diferenciá-los das demais citações presentes no texto.

Momento: diálogos em educação, E-ISSN 2316-3100, v. 26, n. 1, p. 59-73, jan./jun. 2017
} 
positiva para os nativos da ilha. Ao utilizar-se da representação do ambiente natural os filmes nos provocam o pensamento sobre uma discussão bastante marcada pelo campo de saber da Educação Ambiental, a separação entre natureza e cultura. Apesar da fala da lêmure explicitar essa diferenciação, os comportamentos e ações desse grupo são visivelmente marcados pelo comportamento humano. Para Kindel,

Os filmes infantis - desenhos animados, mais especificamente -, utilizam-se de diversos recursos que simplificam e purificam histórias e contos infantis nos quais o ambiente natural tem sido sempre um cenário privilegiado da história. Muitas vezes, eles misturam características humanas e dos demais seres vivos, também através da construção de sociedades animais que repetem as dos humanos. A utilização da natureza como cenário principal e de uma variedade de seres vivos que ganham dimensão no desenho - animais e plantas vistos como dotados de pureza e ingenuidade - acaba por tornar o discurso desse tipo de produção fílmica praticamente inquestionável (2003, p. 30).

Mauro Guimarães (2004, p.26) aponta que essa dicotomia entre homem e natureza "sustenta uma relação desintegrada entre sociedade e natureza, baseada na dominação e espoliação da primeira sobre a segunda, pilares da crise ambiental da atualidade". A natureza assim é entendida como um ambiente em que o humano não se encontra, a natureza como diz Grün, “é aquilo que está 'lá”" (2012, p. 36) [grifo do autor], que só é natureza porque não há presença humana. Quando esse homem adentra essa natureza, seus efeitos são sempre negativos, afim de desbravar, conhecer, organizar e transformar em outro lugar, um lugar onde se pode ser civilizado.

A expressão da lêmure transmite a ideia de que homem e natureza não podem coexistir: onde há um, não pode haver o outro. A esse respeito, o que desejamos sublinhar, é o papel de destaque designado ao homem na relação com a natureza. Ao problematizar um dos aspectos que marcam os tempos modernos, Marise Basso Amaral destaca, entre outros, a posição ocupada pelo homem como centro do mundo. A autora afirma:

[...] o olhar hegemônico sobre a natureza, construído através das representações hegemônicas dominantes de natureza que habitam os livros de história e contos, os livros didáticos, as revistas científicas e os meios de comunicação de massa continuam a constituir uma identidade social que vê na natureza o diferente, o oposto da cultura (2004, p. 146).

Tratando ainda desse antagonismo entre o humano e o natural, vemos que os animais nascidos em cativeiro ou que já tiveram contato exagerado com os humanos, perdem aos poucos seus instintos de sobrevivência, deixando assim sua animalidade de lado e adquirindo características do convívio humano. Exemplo disso vemos no filme Madagascar (2005), onde o leão Alex sente a necessidade de se alimentar e entra em um conflito existencial por não 
querer caçar, já que a maior presa que ele tem à vista é a zebra Marty, seu melhor amigo. O leão aparece representado, então, ao tentar obter alimento, com a juba crespa e desgrenhada, unhas afiadas, locomovendo-se com as quatro patas. Bem diferente do que vemos ao longo do restante do filme, onde ele tem suas feições mais próximas de um humano. Ao fim desse episódio, os pinguins encontram uma solução: oferecer ao Alex peixe cru - como se peixe não fosse também um animal. Nessa cena um dos pingüins aparece caracterizado com elementos da cultura japonesa, preparando um sushi para Alex. As outras personagens se surpreendem com a reação positiva do leão. Neste momento a lêmure oferece a Alex outro animal e ele recusa. Todos comemoram a "mudança" de Alex. Para Kindel,

De qualquer modo, seja qual for o filme, ele só terá sucesso se puder atingir grupos culturais diferentes, mas que de certo modo partilham mitos, crenças, valores e práticas sociais de forma semelhante. E é assim que, por exemplo, a indústria do cinema cria narrativas que cruzam diferentes codificações culturais de pessoas de diferentes nacionalidades (2003, p. 45).

No filme Madagascar 2 (2008), após uma tentativa frustrada de retornar ao zoológico de Nova Iorque, os animais encontram-se mais uma vez em um ambiente que não é o urbano. O avião tripulado por eles acaba caindo em uma reserva na África. Nesta cena a zebra aparece junto com os demais animais ao topo de um penhasco de onde eles observam à distância uma reserva ambiental que encontram na África. Na ocasião, ela afirma: "Isso é que é vida!"; De volta para as raízes, ar fresco!” (MADAGASCAR 2, 2008).

No entanto ao entrar na reserva, eles se deparam com sentimentos controversos: ao mesmo tempo estão em um ambiente que não é o deles, já que consideravam o zoológico de Nova Iorque a sua casa, mas convivem com a sensação de pertencimento aquele lugar. Notase isso quando o leão Alex diz: "Esse é o meu pedaço ancestral!".

É nesse filme também que Alex toma conhecimento da sua história. Ele foi capturado ainda bebê, retirado da reserva e levado ao zoo de Nova Iorque. Encontram nesse novo ambiente também, algumas adversidades naturais, como a seca, por exemplo. E precisam enfrentar os humanos, que desta vez não estão prestando serviço aos animais, antes pelo contrário, encontram-se perdidos também na reserva e, com medo de não sobreviverem, passam a se valer de suas habilidades para dominar a natureza e os animais. Nesse momento, destaca-se uma cena emblemática no filme quando os humanos, perdidos na selva se reúnem ao pé de uma fogueira sob a liderança de uma mulher idosa que lhes acalma, dizendo: "Podem deixar a natureza se aproveitar de vocês ou se aproveitar da natureza... Se a gente venceu lá 
(cidade de Nova Iorque), podemos vencer aqui também" (MADAGASCAR 2, 2008). De acordo com Amaral,

\begin{abstract}
A identidade moderna foi e continua sendo construída através dos processos de produção de identidade que invariavelmente reforçam o antropocentrismo e criam as ferramentas teóricas e sociais que autorizam o ecocídeo. O olhar hegemônico sobre a natureza, construído através das representações dominantes de natureza que habitam os livros de História e contos, os livros didáticos, as revistas cientificas e os meios de comunicação de massa continuam a construir uma identidade social que vê na natureza o diferente, o oposto da cultura (2004, p.146).
\end{abstract}

Essa forma de pensar, herança da ciência moderna, coloca o homem em uma posição superior a natureza. Com isso, esse distanciamento tornou-se cada vez mais evidente, entendendo que "a natureza é puro horror. Nós somos humanos, civilizados, distantes do 'horror' da barbárie do id. Este é o destino da natureza dominada da qual nos distanciamos" (GRÜN, 2012, p.36) [grifo do autor].

Precisamos destacar que, aquilo que dizemos sobre a natureza não é a natureza em si, e sim estereótipos da natureza dadas a partir de nossas experiências, de nossa cultura, daquilo que tomamos por verdade em um determinado momento histórico e não em outro. Para os animais vindos do zoológico, atravessados por diversos aspectos da cultura nova-iorquina marcadas pelas cenas de massagem vivida pela hipopótamo Glória e pelo suculento bife servido como refeição ao leão Alex, por exemplo - a natureza é representada pelo perigo de suas inúmeras adversidades, supostamente mais comuns no meio natural e que não eram presenciadas por eles no zoológico.

Em contrapartida temos as narrativas da lêmure habitante da ilha de Madagascar, assim como dos pinguins - que incitam a zebra Marty a fugir do zoológico, dando início à história - as quais apontam a natureza como um "espaço aberto" (MADAGASCAR, 2005), lugar de liberdade, espaço ancestral.

No filme Madagascar 3 (2012), os animais ainda estão marcados por sentimentos nostálgicos, representados pela saudade que têm da vida no zoológico e por isso mais uma vez começam uma aventura para tentar chegar em Nova Iorque. Após inúmeras tentativas de fuga, pegam carona em um vagão de trem, onde iniciam uma história de revitalização de um circo falido. Constroem relações de amizade com os outros animais circenses e com muita determinação e uma boa dose de imaginação eles finalmente tornam o circo um sucesso e conseguem retornar ao zoológico. Porém, ao final da aventura, ao retornarem ao Zoológico, 
os animais parecem desapontados, o que fica evidenciado na cena em que os quatro amigos aparecem atrás das grades do zoo com expressões que marcam sua decepção.

Se deparam com a pintura na parede do zoo e veem que não se assemelha com a natureza, como eles inicialmente imaginavam. Demonstram, nesse momento, um sentimento de tristeza e de arrependimento em terem feito toda aquela empreitada para o retorno ao zoológico e, por fim, constatam que o lugar não pode mais ser considerado a sua casa. Dessa vez, ao contrário do que ocorrera no primeiro filme - Madagascar, 2005 -, a representação mais forte é de que a natureza seja mesmo o lar desses animais (aculturados). O retorno, tão desejado, ao meio urbano, não faz mais sentido. Principalmente porque, como nos ensina esse conjunto de filmes, nos acostumamos com o espaço urbano, mas nossa "essência" se encontra na natureza.

A partir desse desfecho podemos lançar um questionamento que mobiliza nosso pensamento: que relação é essa que se estabelece entre o homem e a natureza? Ao longo dos três filmes, pode-se perceber significados bem distintos dessa natureza. Primeiro um lugar nostálgico para o qual se quer retornar, depois um lugar desordenado do qual se quer fugir, e por fim a aceitação desse lugar como seu verdadeiro lar. É pertinente destacar que tais questões são colocadas em xeque em nossa sociedade, pois nos encontramos em um momento histórico que permite esse questionamento. Para Ost, vivemos em uma crise de paradigma, uma crise de vínculo:

Esta crise é simultaneamente a crise do vínculo e a crise do limite: uma crise de paradigma, sem dúvida. Crise do vínculo: já não conseguimos discernir o que nos liga ao animal, ao que tem vida, à natureza; crise do limite: já não conseguimos discernir o que deles nos distingue (1995, p.7).

Olhar com as lentes foucaultianas nos permite perceber essas diferentes partículas enunciativas, identificando também o enunciado antropocêntrico, que coloca o homem como centro do mundo, dando condições de dominação humana em relação à natureza. Assim os discursos, fabricados através de diferentes enunciados permeados pelas relações de poder, fazem circular e serem aceitas algumas verdades, ditando nossos modos de agir.

É preciso finalizar destacando que todas essas representações que construímos a respeito do homem e da natureza - assim como de outras coisas - são, segundo Foucault (2009), permeadas por relações de poder que mantém a sociedade em funcionamento. Tais relações são marcadas por aspectos dos campos político e econômico que criam verdades 
sobre o mundo, criam formas de ser, viver e estar no mundo. Imerso no jogo das relações de poder, vemos acontecer o jogo das representações sobre a natureza e o homem em relação a ela. Em relação a isso, Carvalho $(2014$, p.1) afirma que "assim se constrói a imagem de uma relação antagônica e excludente onde de um lado estaria a Natureza e do outro a Humanidade, a Cultura, as relações sociais". Segundo a autora, os artefatos midiáticos evocam ideias de natureza, vida biológica, vida selvagem, flora e fauna. Em que

Essa visão 'naturalizada' tende a ver a natureza como um mundo de ordem biológica, essencialmente boa, pacificada, equilibrada, estável em suas interações ecossistêmicas, o qual segue vivendo como autônomo e independente da interação com o mundo cultural humano. Quando essa interação é focada, a presença humana amiúde aparece como problemática e nefasta para a natureza. (CARVALHO, 2008, p.35) [grifo da autora].

É preciso reiterar que as imagens de natureza não são como pretendem se apresentar, um retrato objetivo e neutro, um espelho do mundo natural, mas traduzem certa visão de natureza, em geral, uma visão naturalizada da natureza.

\section{CONSIDERAÇÕES FINAIS}

Neste artigo, tivemos como objetivo discutir as representações e homem e de natureza presentes na mídia cinematográfica, em especial na sequencia fílmica Madagascar (2005, 2008, 2012). Operando com o conceito de problematização dado pelos estudos foucaultianos, nos debruçamos e colocar sob suspeita alguns discursos naturalizados em nossa sociedade, cutucando nosso pensamento a respeito das "verdades" reverberadas pelos artefatos analisados.

Notamos que os excertos destacados nesta pesquisa corroboram a ideia do homem como aquele que destrói, contamina, polui e faz uso da natureza ao seu favor, mas, ao mesmo tempo, um homem que auxilia, salva e protege. A respeito desse antagonismo, ambas as representações apontam para um centro: o homem, que em sua relação com a natureza dominada, ocupa a posição de dominador.

Temos entendido que tais resultados possam ser pensados como uma reatualização do ideal moderno antropocêntrico, o que nos põem a pensar na produtividade desse artefato cultural nos nossos dias; pelas formas como nossos discursos, nossas formas de ser estar no mundo, em especial na nossa relação com a e na natureza, passam a ser naturalizados.

Interpeladas pela provocação foucaultiana de pensar o pensamento, de problematizar aquilo que nos parece mais enraizado em nossas ações e em nossas vidas, convidamos o leitor 
a não tomar nossas palavras como verdades. Que elas sirvam de gatilhos para outros pensares, para outros modos de nos relacionarmos com e no mundo.

\section{REFERÊNCIAS}

AMARAL, M. B. Natureza e representação na pedagogia da publicidade. In.: COSTA, M. V. e VEIGA-NETO, A. (Orgs.). Estudos Culturais em Educação: mídia, arquitetura, brinquedo, biologia, literatura, cinema... 2.ed. Porto Alegre: Editora da UFRGS, 2004. p. 143 $-171$.

ANDRADE, P. D.; COSTA, M. V. Usos e possibilidades do conceito de pedagogias culturais nas pesquisas em estudos culturais em educação. Textura, Canoas v.17 n. 34 p. 48-63 maio/ago. $2015 . \quad$ Disponível em http://www.periodicos.ulbra.br/index.php/txra/article/viewFile/1501/1140

CAMOZZATO, V.; COSTA, M. V. Vontade de pedagogia - pluralização das pedagogias e condução dos sujeitos. Cadernos de Educação da UFPel, n. 44, jan-abr. 2013. Disponível em https://periodicos.ufpel.edu.br/ojs2/index.php/caduc/article/view/2737

CARVALHO, I. Educação ambiental: a formação do sujeito ecológico. 4 ed. São Paulo: Cortez, 2008.

Educação para sociedades ambientalmente justas. p. 1 - 9. Disponível em: https://www.yumpu.com/pt/document/view/12857634/educacao-para-sociedadessustentaveis-e-isabel-carvalho. Acesso em: 18/03/2014.

FOUCAULT, M. A arqueologia do saber. $6^{\mathrm{a}}$ ed. Rio de Janeiro: Forense Universitária, 2010.

Microfísica do poder. $9^{a}$ ed. Rio de Janeiro: Graal, 2009.

GUIMARÃES, M. Educação Ambiental Crítica. In. Identidades da educação ambiental brasileira / Ministério do Meio Ambiente. LAYRARGUES, P. P. (coord.). Brasília: Ministério do Meio Ambiente, 2004.

GUIMARÃES, L. B. A importância da história e da cultura nas leituras da natureza. ANPED, 2008. Disponível em: http://29reuniao.anped.org.br/trabalhos/trabalho/GT22-1726-- Int.pdf. Acesso em: 06/11/2015.

GRÜN, M. Ética e educação ambiental: a conexão necessária. $14^{\mathrm{a}}$ ed. Campinas: Papirus, 2012.

KINDEL, E. A. A natureza no desenho animado ensinando sobre homem, mulher, raça, etnia e outras coisas mais... Tese de Doutorado, 2003. Disponível em: http://www.lume.ufrgs.br/handle/10183/2504 Acesso em: 23/09/2014 22:43.

MADAGASCAR. Direção: Eric Darnell e Tom McGrath. Produção: Mireille Soria, Teresa Cheng. 1 DVD 86 min. DreamWorks Animation SKG, 2005.

MADAGASCAR 2: os procurados. Direção: Eric Darnell e Tom McGrath. Produção: Mark Swift, Mireille Soria. 1 DVD 89 min. DreamWorks Animation SKG, 2008. Título original: Madagascar: escape 2 Africa.

MADAGASCAR 3: a grande escapada. Direção: Eric Darnell. Produção: Mark Swift, Mireille Soria. 1 DVD $93 \mathrm{~min}$. DreamWorks Animation SKG, 2012. Título original: Madagascar 3: Europe most wanted.

NOGUERA-RAMÍREZ, C. E. O governamento pedagógico: da sociedade de ensino para a sociedade da aprendizagem. 2009. 266f. Tese - Curso de Doutorado em Educação, 
Universidade Federal do Rio Grande do Sul, Porto Alegre. Disponível em http://www.michelfoucault.com.br/files/O\%20governamento\%20pedag\%C3\%B3gico.Da\%20 sociedade $\% 20 \mathrm{do} \% 20$ ensino $\% 20$ para $\% 20 \mathrm{a} \% 20$ sociedade $\% 20 \mathrm{da} \% 20$ aprendizagem.Carlos $\% 20$ Ernesto\%20Noguera-Ramirez.pdf. Acesso em: 15/03/2016

OST, F. A natureza à margem da lei. A ecologia à prova do direito. Lisboa: Instituto Piaget, 1995.

SILVA, T. T. da. Documentos de identidade: uma introdução às teorias do currículo. Belo Horizonte: Autêntica, 1999.

VEIGA-NETO, A. Michel Foucault e os Estudos Culturais. In COSTA, Marisa Vorraber; VEIGA-NETO, Alfredo [et al.]. Estudos culturais em educação: mídia, arquitetura, brinquedo, biologia, literatura, cinema...2. ed. Porto Alegre: Editora da UFRGS, 2004.

WORTMANN, M. L. C. O uso do termo representação na Educação em Ciências e nos Estudos Culturais. Proposições. Revista Quadrienal. Faculdade de Educação - Unicamp. Vol. 12, n1(34) - março/2001.

WORTMANN, M. L. C. Por que se valer do cinema, da mídia, da literatura, da televisão para discutir a natureza/ambiente?. In: ZAKRZEVSKI, S. B.; BARCELOS, V. (Orgs.). Educação Ambiental e Compromisso Social. Erechim: EdiFAPES, 2004. p. 147-161. 